\title{
POST PARTUM HEMORRHAGE; EFFICACY OF BALLOON TAMPONADE IN THE MANAGEMENT
}

1. MBBS, FCPS, MCE (Embryology \& Test Tube baby Monash University Australia). Fellow in Reproductive Endocrionolgy (NUS Singapore). Vice Chancellor, FMU, Faisalabad.

2. MBBS, FCPS

Associate Professor, Head of Radiology Department FMU, Faisalabad.

3. MBBS, FCPS Senior Registrar, Allied Hospital, Faisalabad.

4. MBBS, FCPS

Assistant Professor,

Obst. \& Gynae Department

FMU, Faisalabad.

5. MBBS, FCPS

Senior Registrar,

Allied Hospital, Faisalabad.

Correspondence Address:

Sardar Alfareed Zafar

MBBS, FCPS, MCE

(Embryology \& Test Tube baby

Monash University Australia).

Fellow in Reproductive

Endocrionolgy (NUS Singapore).

Vice Chancellor, FMU, Faisalabad.

alfareedzafar@hotmail.com

Article received on:

24/05/2017

Accepted for publication:

26/08/2017

Received after proof reading: $08 / 09 / 2017$

\begin{abstract}
Sardar Alfareed Zafar ${ }^{1}$, Asim Shaukat ${ }^{2}$, Ayesha Khalid ${ }^{3}$, Ammara Niaz $^{4}$, Shagufta Noor ${ }^{5}$
\end{abstract}
ABSTRACT ... Primary postpartum hemorrhagic, rightly called as obstetrician's nightmare, refers to excessive blood loss of more than $500 \mathrm{ml}$ during the third stage of labour or in the first 24 hours after delivery. It continues to be one of the leading causes of maternal mortality and morbidity all over the world including Pakistan where it is responsible for $21-31 \%$ of maternal mortality and morbidity. Objectives: Objective of study was to determine the efficacy of balloon tamponade in the management of primary PPH, so that a low cast, easy to use technology is available for conserving future fertility by treating postpartum hemorrhage. Settings: Department of Gynae \& Obs, Allied Hospital, Faisalabad. Study Design: Descriptive cross sectional study. Study Period: 6 months from $1^{\text {st }}$ Oct, 2015 to $31^{\text {st }}$ March, 2016. Material \& Methods: All patients delivered vaginally at term (after 37 completed weeks of gestation) who developed PPH due to uterine atony after failure of conventional medical therapy were included in this study. Patient selection was based on inclusion and exclusion criteria. Their demographic profile and efficacy of balloon tamponade was checked in terms of time required to control hemorrahage and need of laparotomy. Results: During study period total no. Of vaginal deliveries were 3000 . Out of these 298 developed PPH, 220 had PPH due to uterine atony and did not respond to conventional medical therapy. The age of patients ranged between 22 and 40 years with mean age of 30 year $( \pm 4.88 \mathrm{SD})$. The parity of the patients ranged between 1 and 14 with the mean parity of $4( \pm 2.26 \mathrm{SD})$. The condom catheter was introduced in all the selected 80 patients and was successful in 73 patients. Conclusions: In developing countries such as Pakistan where the maternal death rate from PPH is very high, this safe, in expensive and easy procedure (it does not require any expertise) can be applied in any situation to save a life and to save the uterus in young patients to conserve reproductive capacity and prevent them from surgery and its morbidity. This will protect the patients from irreversible shock and even death with a success rate of $85-95 \%$.

Key words: $\quad$ Postpartum Hemorrhage, Balloon Tamponade, Uterine Atony.

Article Citation: Zafar SA, Shaukat A, Khalid A, Niaz A, Noor S. Post-partum haemorrhage; efficacy of balloon tamponade in the management. Professional Med $\mathrm{J}$ 2017;24(9):1347-1353. DOI:10.17957/TPMJ/17.4183

\section{INTRODUCATION}

Primary postpartum hemorrhage, rightly called as obstetrician's nightmare, refers to excessive blood loss of more than $500 \mathrm{ml}$ during the third stage of labour or in the first 24 hours after delivery. ${ }^{1}$ It continue to be one of the leading causes of maternal mortality and morbidity all over the world ${ }^{2}$ including Pakistan where it is responsible for $21-31 \%$ of maternal mortality and morbidity. ${ }^{3}$

It's an obstetric catastrophe leading to hermorrhagic shock and even death. ${ }^{4}$ For the arrest of hemorrhage medical and surgical measures are employed that involved uterine massage, utrotonic infusions use of prostaglandin analogues, artery ligation (both uterine \& internal iliac) and ultimately the most drastic measure that is hysterectomy with loss of fertility and other short term and long term sequelae.

A lot of conservative procedures have been developed and adapted over the years involving balloon tamponade techniques, radiological interventions (internal iliac embolization) and brace sutures (B-lynch) to preserve future fertility. ${ }^{5}$ limitations of these procedure are: radiological interventions need expertise and local facilities. ${ }^{6}$ 
${ }^{6} \mathrm{~B}-$ lynch needs laparotomy but balloon tamponade technique that involves creation of tamponade with the help of various types of balloons inside the uterine cavity to compress the open uterine sinuses has gained popularity over the past few year especially in cases of failed medical treatment.

After the failure of medical measures the difficulty in the decision to perform a laparotomy may be due to in experience or the concern of preserving future fertility. The role of balloon tamponade comes here after excluding retained tissue and traumatic causes of hemorrhage. It will not only help to avoid unnecessary surgery but will also predict within minutes whether bleeding is likely to stop or surgery is required. It will reduce the blood loss and need of blood transfusions even if surgery is needed. Review of literature tells us its success rate of 85 to 95 precent ${ }^{5 i n}$ the form of arrest of hemorrhage and avoidance of surgical intervention with a mean requirement of 3.2 units of blood. It is simplest, easiest, least invasive, most rapid technique and is a reasonable option in postpartum hemorrhage refractory to medical treatment.

\section{METHODOLOGY}

\section{Study Design}

Descriptive cross-sectional

\section{Settings}

Department of Gynae \& Obs, PMC and its affiliated Allied hospital Faisalabad.

\section{Period}

Six month.

\section{Sample Size}

Eighty patients were included.

\section{Sampling Technique}

Non-probability Consecutive

\section{Inclusion Criteria}

All the patients with primary $\mathrm{PPH}$ being delivered vaginally at term (after 37 completed weeks of gestation) in labour room having uterine atony (relaxed uterus) as the cause of hemorrhage and not responding to conventional medical treatment.

\section{Exclusion Criteria}

Patients of PPH with previous surgery (to avoid scar dehiscence, which can act as confounding variable by causing hemorrhage) having genital tract trauma or retained tissue as cause of hemorrhage (to control bais as different cause of hemorrhage behave differently to corrective measures) or having infection (as it can flare up infection) such as case of chrioamnionitis (infection of fetal membrance) where excluded.

\section{Data Collection Procedures}

Patient fulfilling inclusion criteria were selected. After getting informed written consent procedure was started. After aseptic measures in lithotomy position, cleaning of vulva and surrounding area was done with pyodine. A condom was attached to 16 No. Foley's catheter by black silk No. 1. Under minimal analgesia with the help of Cusco's speculum and sponge holding forceps (to grasp anterior margin of cervix) condom catheter was interested in the uterus with another sponge holding forceps. It was then inflated with 250$300 \mathrm{ml}$ of isotonic warm saline solution until the distended balloon became just visible at cervical canal. The proximal end of catheter was folded and tied with thread so that the saline solution could not escape. Rolled gauze was packed in vagina to keep the inflated condom in place. An intravenous drip containing oxytocin (4050 units $/ 500 \mathrm{ml}$ ) was kept for at least 8 hours to maintain uterus contracted. Intravenous broad spectrum antibiotics were commenced for first 24 hours. Condom catheter was retained for 24-48 hours. Parameters including urine output with the help of indwelling catheter, blood pressure, pulse rate, temperature, oxygen saturation, fundal height assessment and vaginal blood loss were monitored. Patients responding to the technique were stabilized and monitored. Once the parameters were within normal limits, the balloon was deflated in 2 stages 2 hours apart and the patients were observes for any active bleeding. Following variables were noted. In each patient.

1. Time required to hemorrhage 


\section{Need of laparotomy}

\section{Data Analysis}

The collected data was entered into SPSS version 10 and analyzed. The quantitative variables (Age, parity) were presented as mean and standard deviation and qualitative variable i.e ( time required to control hemorrhage and need of laparotomy) were presented as frequency and percentage.

\section{RESULTS}

During six months period total number of deliveries were 3000 . Out of these 298 patients went into post-partum hemorrhage. Thus frequency of PPT was $9.99 \%$ Among 298 patient, $73 \%$ (220 patients) had uterine atone, out of these 220 patients, 80 patients, were selected who did no respond to medical treatment. Demographic characteristics (Age, parity) and other variables i.e time required to laparotomy were studied. The age of patient ranged between 22 and 40 year with mean age was 30 year with mean age was 30 years $( \pm 2.26$ $\mathrm{SD})$.

Out of 80 patients, 4 patients (5\%) were primigravida, 44 patients (55\%) were multigravida, 32 patients (40\%) were grand multigravida.

Bleeding stopped in 73 patients within 15 minutes and there was no need of laparotomy in these patients. Thus the success rate of balloon tamponade was $91 \%$. None of these patients went into irreversible shock. The condom catheter was removed after $24+-48$ hours. There was no intrauterine infection documented by clinical signs and symptoms. In the remaining 7 patient bleeding could not stopped within 15 minutes aid urgent laparotomy was performed D.B- lynch was applied on all these 7 cases (8.75) successful in 4 cases $(5 \%)$, failed in 3caded (3.75).

\begin{tabular}{|c|c|c|}
\hline Age in Years & No. of Patients & Percentage \\
\hline $21-25$ & 12 & $15 \%$ \\
\hline $26-30$ & 37 & $46 \%$ \\
\hline $31-35$ & 19 & $24 \%$ \\
\hline $36-40$ & 12 & $15 \%$ \\
\hline Table-I. Demographic characteristics: \\
\hline
\end{tabular}

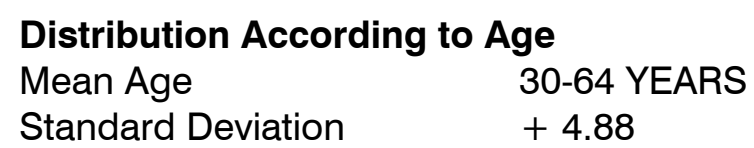

Age group

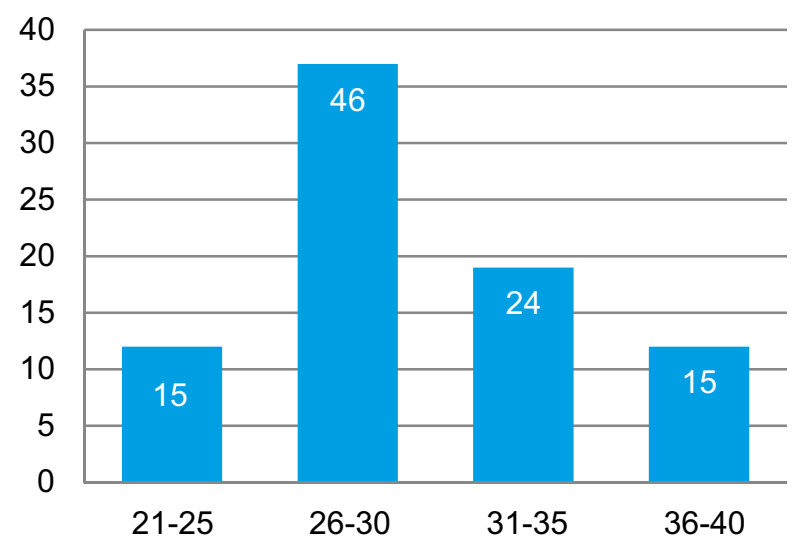

Figure 1

\begin{tabular}{|l|c|c|}
\hline \multicolumn{1}{|c|}{ Parity } & No. of Patients & Percentage \\
\hline Primigravida & 4 & $5 \%$ \\
\hline G2-G4 & 44 & $55 \%$ \\
\hline > G4 & 32 & $40 \%$ \\
\hline
\end{tabular}

Table-II. Distribution according to parity:

\section{Distribution According to Parity \\ Mean Parity $\quad 4.13$ \\ Standard Deviation $\quad+2.26$}

\section{Time req. to control hemorrhage}

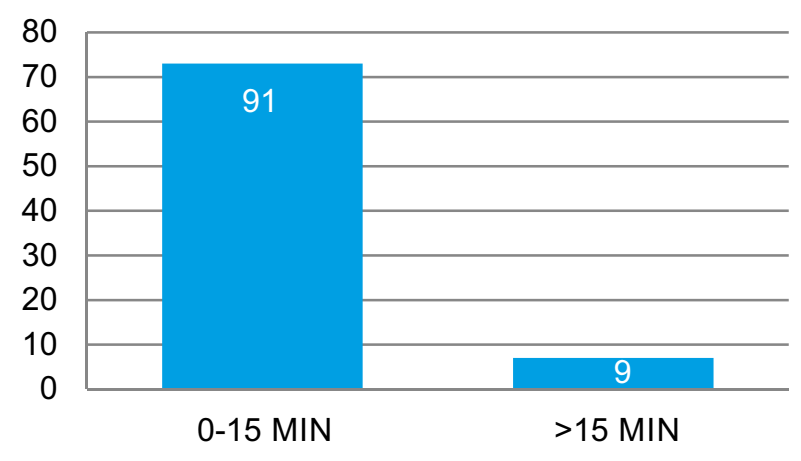

Figure 2 


\begin{tabular}{|l|c|c|}
\hline Need of Laparotomy & No. of Patients & Percentage \\
\hline No & 73 & $91.3 \%$ \\
\hline Yes & 7 & $8.8 \%$ \\
\hline \multicolumn{2}{|c|}{ Table-IV. Distribution according to need of } \\
laparotomy:
\end{tabular}

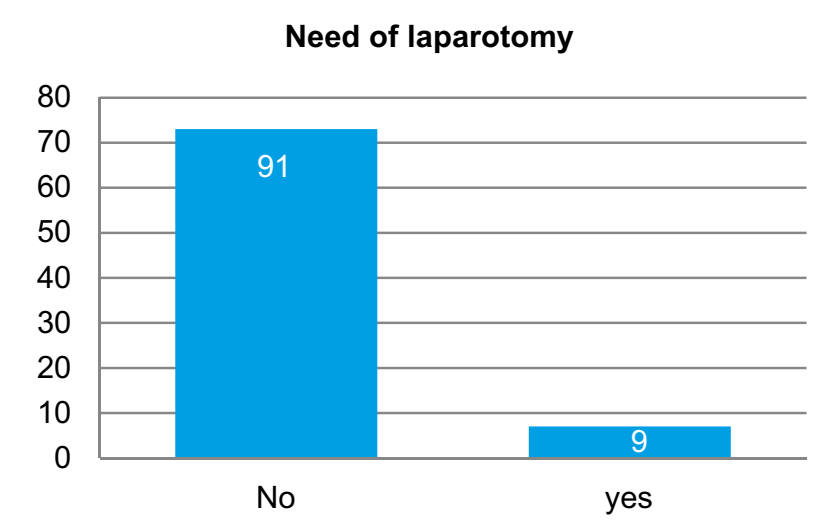

Figure 3

\begin{tabular}{|l|c|c|}
\hline \multicolumn{1}{|c|}{ Outcome } & No. of Patients & Percentage \\
\hline Successful & 73 & $91.3 \%$ \\
\hline Unsuccessful & 7 & $8.8 \%$ \\
\hline Total & 80 & $100 \%$ \\
\hline \multicolumn{2}{|c|}{ Table-V. Distribution of outcome: } \\
\hline
\end{tabular}

\section{DISCUSSION}

The most common cause of Maternal Mortality is postpartum hemorrhage, accounting for one third of maternal deaths.

Although most cases can be treated with medication (prostaglandins, oxytocin and uterine massage), about $10 \%$ of the woman with $\mathrm{PPH}$ require major surgical procedures and even hysterectomy with a disastrous consequence of loss of future fertility.

When the failure of medical treatment has occurred, before resorting to the ultimate solution of PPH that is hysterectomy, it is important to have conservative methods of management.

A variety of conservative techniques have been discovered and employed at this very point in the management of $\mathrm{PPH}$, including application of compression sutures, pelvic devascularization (ligation of uterine, ovarian, internal iliac arteries), radiological intervention (arterial embolisation) and tamponade techniques (uterine packing or balloon tamponade). Each method has benefit and risks. In most cases the above mentioned procedures are effective in avoiding hysterectomy, but delay in carrying out the procedure due to lack of expertise and facilities carries a poor prognosis. B-Lynch suture compresses the uterus without compromising major vessels. The advantage of this procedure is that the identification of specific blood vessels is not required, which is a difficult part in ligation of arteries. Although helpful in caesarean section, it otherwise requires a laparotomy in an already compromised patient.

Pelvic devascularization also requires laparotomy and expertise, and there is a potential risk of ligature of external iliac vessels, ureteric injury, and further hemorrhage.

Similarly, radiological interventions need expertise and local facilities which are not available even in most of the tertiary care centres of our country.

Among the conservative techniques tamponade techniques have gained popularity. They involve creation of tamopnade inside the uterine cavity to compress open uterine sinuses. This can be done either by uterine packing or balloon tamponade.

Once the medical measures fail, the best conservative method employed at this point is balloon tamponade as it does not need laparotomy. It is easy, quick, does not require expertise and facilities. It not only diminishes blood loss but also it predicts within minutes whether bleeding is likely to stop or surgery is required that is it acts as a diagnostic tamponade test. It decreases the No. of blood transfusion even if surgery is needed.

Various types of balloons have been used in this purpose. $30 \mathrm{ml}$ Foley catheter, SengstakenBlakemore tube, Rusch urologic hydrostatic balloon catheter and condom catheter have been employed. $30 \mathrm{ml}$ Foley balloon catheters only hold $150 \mathrm{ml}$ before the burst so their effectiveness in a uterus beyond 20 weeks of gestation is doubtful. The Sengstaken-Blakemore tube is complex to use and is very expensive. The present study was carried out in Allied Hospital Faisalabad from 
$1^{\text {st }}$ Oct 2015 to $31^{\text {st }}$ March, 2016. The incidence of PPH was found to be $9.99 \%$. While range of $5-17 \%$ have been reported following deliveries in the UK. All major studies showed incidence near to $10 \%$. Cameron et al concluded in his study that Postpartum Hemorrhage is a potentially lifethreatening complication of childbirth occurring in up to $10 \%$ of birth. ${ }^{8}$ Shamoona from Federal Government Services Hospital, Islamabad, reported a frequency of $3.7 \%-8.6 \% .^{9}$ Roohi et al showed frequency of $13 \%$ in her study done in Punjab Medical College and its affiliated hospital Faisalabad. ${ }^{10}$ Richard J German showed incidence of $9.9 \%$ in randomized controlled trail of India. ${ }^{11}$ Fauzia Rizvi from Dublin Ireland quoted incidence of $5 \%$ in her study done in May 2004.12 in developing world incidence of PPH is higher because of lack of antenatal care, transportation facilities, non availability of inject able uterotonics, their storage difficulties, lack of guideline and proper staff education and lack of blood bank availability.

In our study, $70 \%$ (220 patients) had uterine atony. These findings were similar to study done by Fauzia Rizvi in which in which $76 \%$ developed PPH due to uterine atony. ${ }^{12}$ The commonest causes was uterine atony in $54 \%$ cases included by Zohra Khanum. ${ }^{13}$ Fehmida et al concluded in postpartum hemorrhage: still a challenge that commonest cause of $\mathrm{PPH}$ was atonic uterus $(65 \%)$ followed by traumatic lesions $(33 \%)$ and retained placenta (27\%)..$^{14}$ Lumaan Sheikh et al concluded that most important cause was uterine atony in his study done in Agha Khan Hospital found that 18 patients $(56.3 \%)$ had uterine atony. ${ }^{15}$

In our study mean age of patients suffering from $\mathrm{PPH}$ is 30 years $( \pm 4.88)$ which is similar to Fauzia Rizvi showed a mean age group of 27.6 years. ${ }^{12}$ in another study done in Tanzania showing PPH more prevalent in 20-30 years which is prime reproductive age group. ${ }^{16}$ In Africa where problem is more prevalent have shown mean age group of 24 years. Hofmeyr reported mean age of 27.1 years. ${ }^{17}$ Walraven $\mathrm{G}$ showed mean age of 24.6 years. ${ }^{18}$ In Africa where PPH appears to be more prevalent, studies had shown that at least $70 \%$ of woman are less than 30 years of age. ${ }^{16}$
Regarding parity, 55\% were multipara, $40 \%$ cases were grand multipara. Arshad Chohan et al concluded is hid study that major predisposing factor was grand multiparity which was in twentyfive $(50 \%)$ patients. ${ }^{19}$ Fahmida Shaheen et al concluded multiparity in $45 \%$ of cases. ${ }^{14}$ The elevated risk associated with multiparity in this study was compatible with the finding of other studies. Higher frequency of postpartum hemorrhage is contract. However Fauzia Rizvi et al stated in her study that grand multiparity is no longer considered to be risk factor for postpartum hemorrhage. ${ }^{12}$

The efficacy of balloon tamponade was assessed by its ability to arrest hemorrhage within $15 \mathrm{~min}$ and the need of laparotomy. The success rate $80 \%$ to $100 \%$ has been reported in previous studies, the success rate of $91 \%$ was observed in my study. A study done in 2003 by G.S. Condous and colleagues showed success rate of more than $87 \%$ which is similar to the success rate of my study. ${ }^{21}$ a systemic review of conservative management done by Doumouchtsis and colleagues done in 2007 showed a success rate of $84 \%$ for balloon tamponade. Other two studies done one bakri balloon and sengstaken tube showed success rate of $80 \% .{ }^{20}$

So the use of least invasive, easiest, and most rapid technique of balloon tamponade should be considered as the first step in the management of intractable PPH, which is not due to genital tract trauma or retained tissue, and which does not respond to medical treatment.

\section{CONCLUSION}

$\mathrm{PPH}$ is a major cause of maternal mortality and serve morbidity in the form of loss of future fertility especially in developing countries like Pakistan. This PPH related mortality and disastrous morbidity of loss of fertility can be reduces if effective conservative measures are employed before resorting to invasive surgical procedure like hysterectomy.

My study concluded that balloon tamponade with condom catheter is the technique which is safe, quick, easy to perform, cost effective, and can be 
effectively employed after the failure of medical measures to reduce hemorrhage related mortality in $\mathrm{PPH}$ and preserve future fertility by preserving the reproductive organs.

This technique not only reduce the blood loss and the need of surgical intervention but it acts as a diagnostic test also which predicts within minutes whether bleeding is likely to stop or surgery is required.

In remote areas where primary health care providers are unable to detect or repair the injury in those cases, this intrauterine tamponade followed by vaginal packing will minimize the blood loss until the patient's arrival to the hospital, which will protect the patient from irreversible shock and even the death. So this easy and economic tamponade technique with the help of condom catheter should be employed at all level of health care when medical management is not effecting to control the bleeding in PPH.

Copyright@ 26 Aug, 2017.

\section{REFERENCES}

1. Rogers MS, Chang AMZ. Postpartum hemorrhage other problems of the third stage. In: James DK, Steer PJ. Weiner CP, Gonik B. editors. High risk pregnancy management options. $3^{\text {rd }}$ ed. Philadelphia: Saunders, 2006; 1559-78.

2. Keriakos R, Mukhopadhyay A. The use of the Rusch balloon for management of severe postpartum hemorrhage. J Obstet Gynaecol 2006; 26:255-8.

3. Shaheen B, Hassan L. Postpartum hemorrhage: a preventable cause of maternal mortality. J Coll Physicians Surg Pak 2007; 17:607-10.

4. Ikechebelu JI, Obi Ra, Joe-ikechebelu NN. The control of postpartum hemorrhage with intrauteme Foley catheter. J Obstet Gynaecol 2005; 25:70-2.

5. Doumouchtsis SK, Papageorghiou AT, Arlkumaran S. Systematic review of conservative management of postpartum hemorrhage: What to do when medical treatment fails. Obstet Gynaecol Surv 2007; 62:540-7.

6. Paterson-Brown S. Obstetric emergencies. In: Edmonds DK, edition. Dewhurst's textbook of obstetrics \& gynecology. $7^{\text {th }}$ ed. Oxford: Blackwell. 2007; 145-58.

7. WHO. World health report 2005-make every mother and child count. Geneva: World Health Organization:
2005.

8. Cameron CA, Roberts CL, Bell J, Fischer W. Getting an evidence-based post-partum hemorrhage policy into practice. Aust N Z J Obstet Gynaecol 2007; 47:169-75.

9. Naqvi S, Makhdoom T. Conservative management of Primary Postpartum Hemorrhage. J Coll Physicians Surg Pak 2004; 14:296-7.

10. Roohi M, Ali R. Primary Atonic Postpartum Hemorrhage (PPH); conservative surgical approach. Professional Med J 2004; 11:181-5.

11. German R J, Kodkany B S, Goudar S S, Geller S E, Naik $\vee A$ and Bellad $M B$, et al. Oral misoprostrol in preventing postpartum hemorrhage in resourcepoor communities: a randomized controlled trial. Lancet 368; 2006:1248-53.

12. Ruzvu F, Mackey R, Mc Kenna P, Geary M. Successful reduction of massive postpartum hemorrhage by using guidelines and staff education. BJOG 2004; 111:495-8.

13. Khanum Z. Primary Postpartum hemorrhage; effective treatment modalities. Ann King Edward Med Coll. 2005; 11:17-9.

14. Shaheen F, Jabeen J. Postpartum Hemorrhage: still a challenge. J Rawal Med Coll 2003; 7;7:77-81.

15. Sheikh L, Zubri N, Riaz R, Rizvi J. Massive primary postpartum hemorrhage: setting up standards of care. J Pak Med Assoc 2006; 56:26-31.

16. Prata N, Mbaruku G, Campbell M, Potts M, Vahidnia F. Controlling postpartum hemorrhage after home births in Tanzania. Int J Gynoecia Obstet 2005; 90:515 .

17. Hofmeyr GJ, Ferreira S, Nikodem VC, et al. Misoprostol for treating postpartum haemorrhage: a randomized controlled trial. BMC Pregnancy Childbirth 2004; 4:16.

18. Walraven G, Dampha Y, Bittaye B, Sowe M, Hofmeyr $\mathrm{J}$. Misoprostol in the treatment of postpartum haemorrhage in addition to routine management; a placebo randomized controlled trial. BJOG. 2004; 111:1014-7.

19. Chohan A, Butt F, Mansoor H, Falak T. Primary post partum hemorrhage: outcome of different treatment measure. Biomedica 2006; 22:16-20.

20. Doumouchtsis SK, Papageorghiou AT, Vernier C, Arulkumaran S. Management of postpartum hemorrhage by uterine balloon tamponade: prospective evaluation of effectiveness. Acta Obstet Gynaecol Scand 2008; 87:849-55. 
21. Condous GS, Arulkumaran S, Symonds I, Chapman $R$, Sinha A, Razvi K. The tamponade test in the management of massive postpartum hemorrhage. Obstet Gynaecol 2003; 101:767-72.

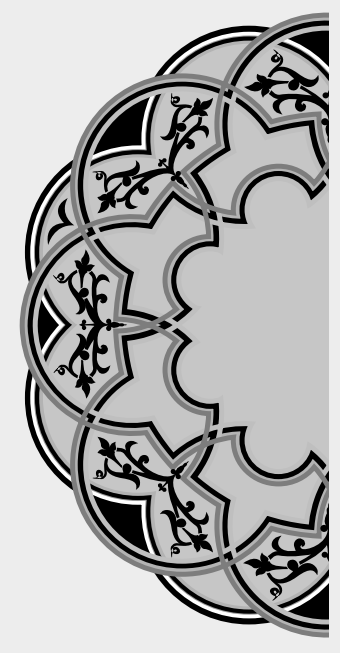

"When setting out on a journey, do not seek advice from those who have never left home."

\section{Rumi}

\section{AUTHORSHIP AND CONTRIBUTION DECLARATION}

\begin{tabular}{|c|l|l|l|}
\hline Sr. \# & \multicolumn{1}{|c|}{ Author-s Full Name } & \multicolumn{1}{|c|}{ Contribution to the paper } & Author=s Signature \\
\hline 1 & Sardar Alfareed Zafar & 1st Author \\
\hline 3 & Asim Shaukat & Ayesha Khalid & 3rd Author \\
4 & Ammara Niaz & 4th Author \\
5 & Shagufta Noor & 5th Author & \\
\hline
\end{tabular}

